\title{
Simulation Techniques for Design and Control of a Waste Heat Recovery System in Marine Natural Gas Propulsion Applications
}

\author{
Marco Altosole ${ }^{1}$, Ugo Campora ${ }^{2}$, Silvia Donnarumma ${ }^{3, *(1)}$ and Raphael Zaccone ${ }^{3}$ \\ 1 Department of Industrial Engineering, University of Naples "Federico II", School of Polytechnic and Basic \\ Sciences, University of Naples, 80125 Napoli, Italy; marco.altosole@unina.it \\ 2 Department of Mechanical, Energy, Management and Transportation Engineering, University of Genoa, \\ Polytechnic School, 16145 Genoa, Italy; Ugo.Campora@unige.it \\ 3 Department of Electrical, Electronic, Telecommunications Engineering and Naval Architecture University of \\ Genoa, Polytechnic School, 16145 Genoa, Italy; raphael.zaccone@edu.unige.it \\ * Correspondence: donnarumma@dime.unige.it; Tel.: +39-010-353-2387
}

Received: 9 October 2019; Accepted: 17 October 2019; Published: 6 November 2019

\begin{abstract}
Waste Heat Recovery (WHR) marine systems represent a valid solution for the ship energy efficiency improvement, especially in Liquefied Natural Gas (LNG) propulsion applications. Compared to traditional diesel fuel oil, a better thermal power can be recovered from the exhaust gas produced by a LNG-fueled engine. Therefore, steam surplus production may be used to feed a turbogenerator in order to increase the ship electric energy availability without additional fuel consumption. However, a correct design procedure of the WHR steam plant is fundamental for proper feasibility analysis, and from this point of view, numerical simulation techniques can be a very powerful tool. In this work, the WHR steam plant modeling is presented paying attention to the simulation approach developed for the steam turbine and its governor dynamics. Starting from a nonlinear system representing the whole dynamic behavior, the turbogenerator model is linearized to carry out a proper synthesis analysis of the controller, in order to comply with specific performance requirements of the power grid. For the considered case study, simulation results confirm the validity of the developed approach, aimed to test the correct design of the whole system in proper working dynamic conditions.
\end{abstract}

Keywords: ship energy efficiency; waste heat recovery; natural gas; steam turbine; control; power grid dynamics

\section{Introduction}

Increasingly restrictive regulations on pollutant emissions from ship diesel engines [1,2] have been recently issued by the International Maritime Organization (IMO). Specific limitations in sulfur and nitrogen oxides have been introduced in the current emission control areas (European North Sea, English Channel, Baltic Sea, east and west coasts of North America) but they will soon also be applied to some new additional extensions (e.g., Mediterranean Sea [3]). With regard to carbon dioxide $\left(\mathrm{CO}_{2}\right)$, it is estimated by means of the Energy Efficiency Design Index (EEDI), defined by IMO as the $\mathrm{CO}_{2}$ production per transport work of the vessel (i.e., grams of $\mathrm{CO}_{2}$ per ton-mile) $[4,5]$. New ships will have to comply with EEDI, leading to a continuous search for energy-efficient technical solutions, as using more eco-friendly fuels (e.g., LNG [6-9]).

A further abatement of pollutant emissions is possible by recovering the waste heat from the exhaust gas of the ship engines, in order to produce enough steam to drive an electric turbogenerator. This solution can obviously minimize diesel generator's power and emissions 
of the vessel [10-13]. The simultaneous use of gas-fueled engines together with Waste Heat Recovery (WHR) systems can strongly improve the ship energy efficiency, with significant fuel savings and emissions reduction [14-19]. Natural gas is not only an eco-friendly fuel but it can also offer a better waste heat recovery. The absence of sulfur content actually makes this fuel free from corrosion phenomena due to the acid sulfur production in the exhaust pipes. Therefore, the exhaust gas temperature at the funnel outlet can drop much below $170{ }^{\circ} \mathrm{C}$, i.e., the temperature lower limit usually adopted in diesel engine applications since such value is considered quite far from the sulfuric acid dew point $[18,19]$. Therefore, a larger difference in exhaust gas temperature between inlet and outlet of the WHR system may provide a greater steam production to be exploited in the turbogenerator [17]. However, the most important manufacturers of marine engines, as Wärtsilä and MAN, propose WHR steam plants for diesel propulsion applications $[10,18]$, while currently they do not consider in the same way such technological solutions for Dual-Fuel (DF) engines. The best possible exploitation of the exhaust gas temperature in LNG propulsion mode is then considered theoretically but not yet in practice. The main reason is due to the installation cost [14] to be paid for the energy efficiency improvement of LNG propulsion system that is already more environmentally friendly than diesel ones. Moreover, the higher prices of DF engines and the still poor diffusion of natural gas in marine propulsion discourage the shipowners from investing additional money. Therefore, a reliable tool for decision-makers, based on specific indicators to assess the economic, environmental, and social sustainability of such a technology, can be fundamental [19]. To this end, the correct sizing of each component has to be ensured during the design phase, by verifying a proper plant performance both in steady-state and transient conditions. Once the technical feasibility of the system is checked, additional considerations for the sustainability of project can be carried out.

By time-domain simulation, it is possible to assess the steam-powered turbogenerator performance taking into account also its control system behavior, in order to avoid excessive frequency variations of the ship power grid. The authors' research group has already adopted simulation techniques to design and test the propulsion controllers of several Italian vessels through a "trial and error" method [20-24], while in the present new application, the simulation approach proposed for the steam turbine representation allows to define a more effective design methodology of the controller.

\section{Simulation Model}

The dynamic behavior of the WHR steam plant is reproduced by means of a Matlab-Simulink time-domain simulator.

The WHR configuration examined for the ship steam production is illustrated in Figure 1: the exhaust gas heat of a marine DF engine is recovered by the Heat Recovery Steam Generator (HRSG), mainly consisting of an Economizer (E) and an Evaporator (EV). Then some saturated steam is produced in the Steam Drum (SD) to feed a turbogenerator, i.e., a Steam Turbine (ST) driving an alternator (Electric Generator, EG). The saturated water, derived from the condensation of the waste steam, is extracted from the Steam Condenser (SCO) through the Steam Condensing Pump (SCP). After being preheated in the Jacket Water (JW), the water is collected in the Heat Water Tank (HWT). Then, the Main Feed Pump (MFP) moves the hot water to the economizer feeding SD (from which a part of steam is taken to meet the steam users demand of the ship). On the way, the hot air in the engine Scavenger (SC) is used to increase the water heating efficiency. 


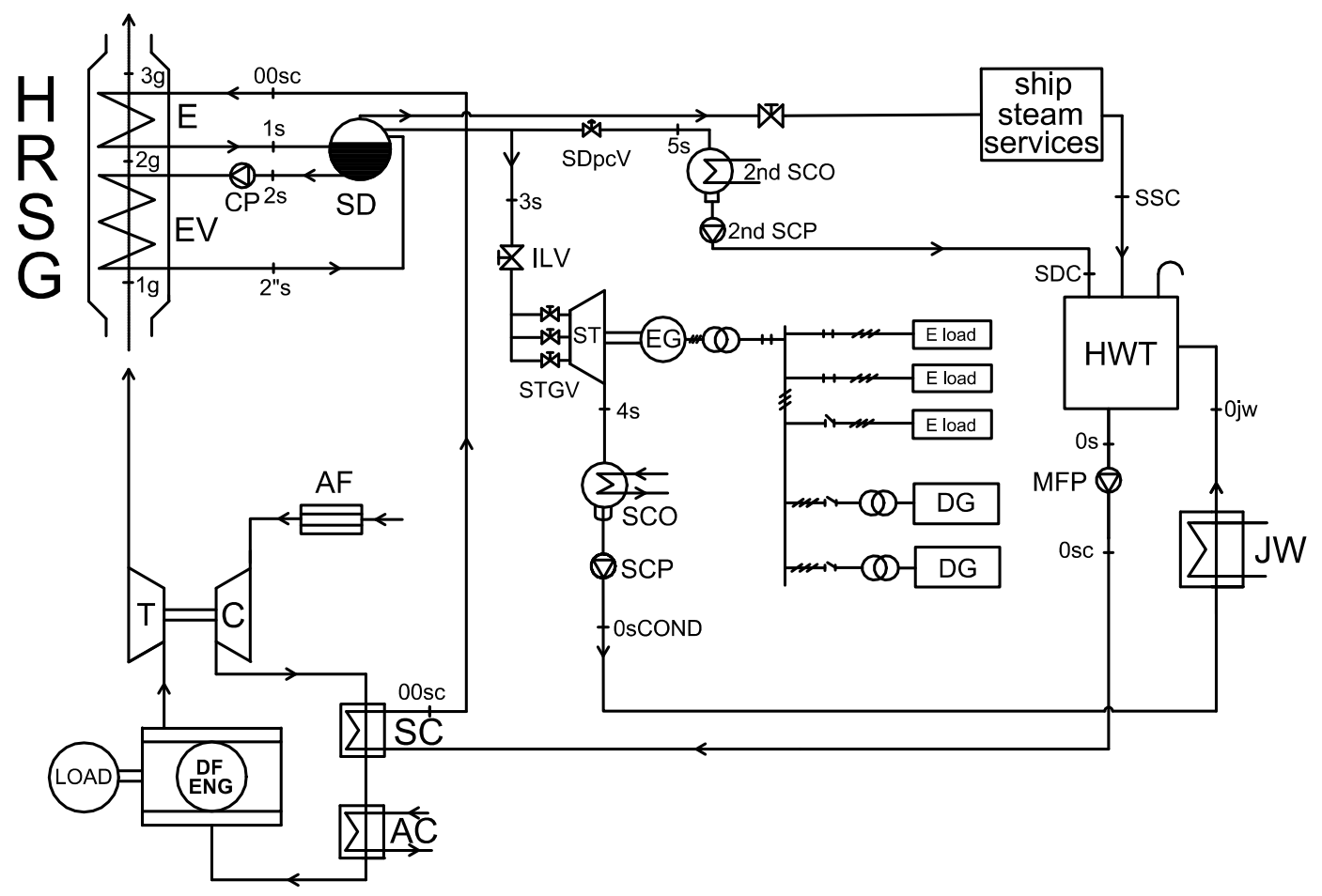

Figure 1. Waste Heat Recovery (WHR) system configuration.

The proposed DF engine-WHR system configuration is considered for an existing crude oil tanker, currently equipped with a traditional diesel propulsion plant. In the new propulsion scheme, the main engine and diesel generators are replaced with a MAN 51/60 18V DF four-stroke [25] and a steam-powered turbogenerator, respectively (the main performance data are shown in Table 1). The ship electric energy demand is about $800 \mathrm{~kW}$, while a steam flow rate of $0.38 \mathrm{~kg} / \mathrm{s}$ is needed for the ship thermal users.

Table 1. Engines performance data.

\begin{tabular}{ccc}
\hline Performance Data & DF Engine & Steam Turbine \\
\hline Maximum continuous power (MW) & 17.55 & 1.00 \\
Maximum continuous speed (rpm) & 500 & 10,400 \\
\hline
\end{tabular}

Regarding the chemical and thermodynamic characteristics of the engine exhaust gas, quite different in diesel or gas mode, the WHR components sizing is optimized for LNG propulsion [15], considering a really sporadic use of diesel oil. Under this assumption, the production of the ship electric energy can be completely ensured by the single steam-powered turbogenerator, thus avoiding additional fuel consumption from diesel generators (named DG in Figure 1).

The simulation input data are mainly represented by the electric power demand of the vessel together with the flow rate and temperature of the exhaust gas from the main engine. Through the developed numerical tool, the dynamic performance of the steam powered turbogenerator can be assessed during the ship power grid transients and for a given DF engine working condition.

\subsection{Main Basic Equations}

The whole numerical model consists of several submodules representing the behavior of WHR plant components as steam drum, heat exchangers, and steam turbine. 
The steam drum numerical modeling is based on the continuity and energy equations over time $t[16,26]:$

$$
\begin{gathered}
\frac{d \rho}{d t}=\frac{1}{V} \sum\left(M_{i}-M_{o}\right) \\
\frac{d \rho U}{d t}=\frac{1}{V} \sum\left(M_{i} h_{i}-M_{o} h_{o}\right)
\end{gathered}
$$

where $\rho$ is the density; $M_{i}$ is the inlet mass flow rate; $M_{o}$ is the outlet mass flow rate; $U$ is the specific internal energy; $V$ is the volume; $h_{i}$ is the inlet specific enthalpy; $h_{o}$ is the outlet specific enthalpy.

The heat exchangers dynamics is evaluated through the wall temperature $\left(T_{w}\right)$ equation:

$$
C_{w} \frac{d T_{W}}{d t}=Q_{g}^{\prime}-Q_{s}^{\prime}
$$

where $C_{w}$ is the wall thermal capacity; $Q_{g}^{\prime}$ is the gas heat flow; $Q_{s}^{\prime}$ is the steam heat flow.

In Figure 2, the Matlab-Simulink scheme of the overall WHR steam plant dynamic simulator is reported. In the figure only the main parameters exchanged between the modules are visualized. In this model, the main input parameters are the diesel engine exhaust gas temperature and mass flow rate, respectively, $T \_1 g$ and $M \_1 g$, and the steam turbine required speed ( $N \_S T$ req). In the same figure, the main simulator output parameter is the steam turbine brake power (ST power). In the ST and speed governor module, a Proportional-Integral-Derivative (PID) governor maintain the ST speed (N_ST in to the required value acting on the Steam Turbine Governing Valves (STGVs) (visualized in Figure 1).

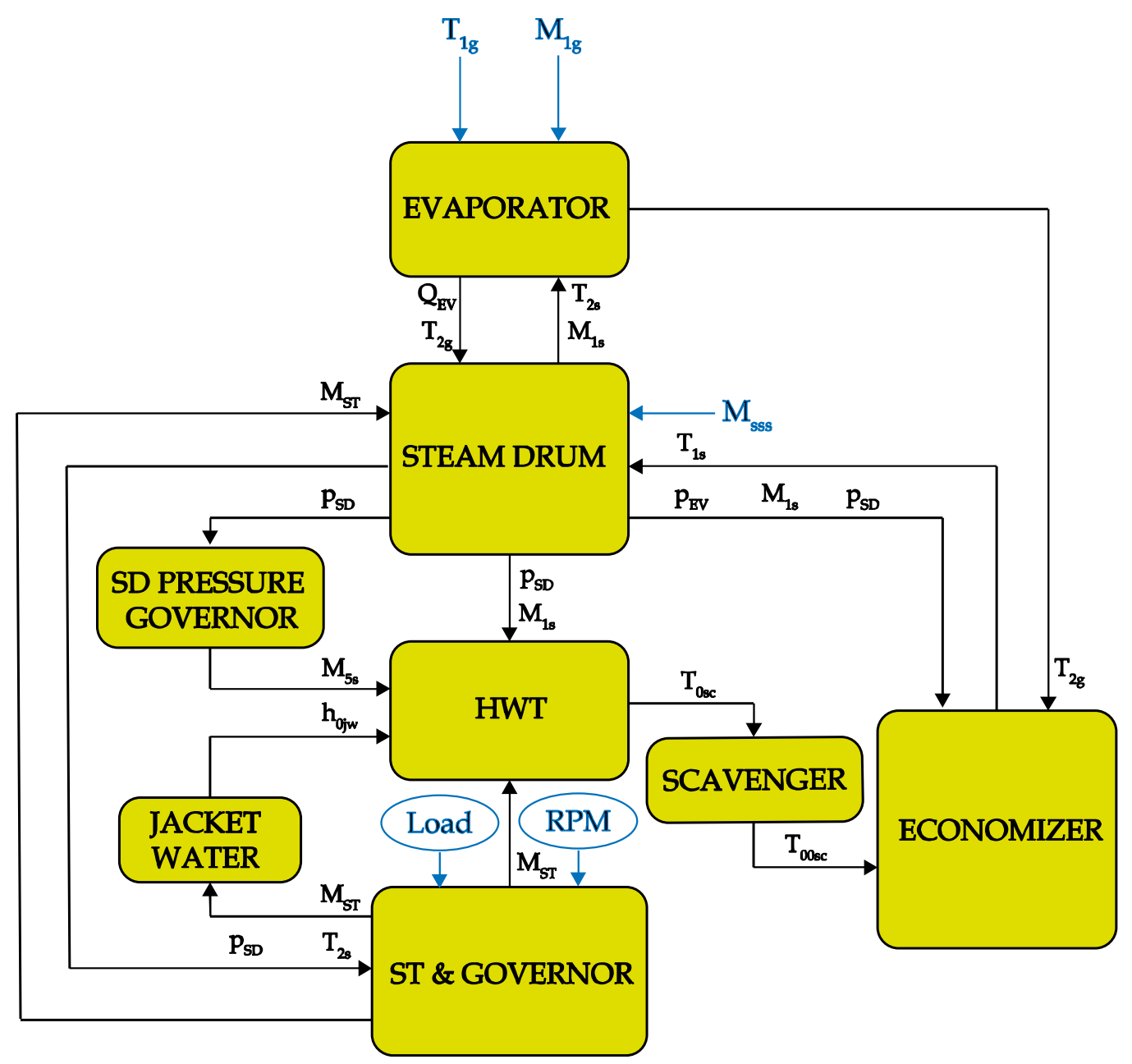

Figure 2. WHR steam plant Matlab-Simulink transients scheme. 
In the WHR steam plant transients calculation, the more important component among the heat exchangers is the evaporator steam drum (SD in the plant scheme of Figure 1 and STEAM DRUM in the Simulink scheme of Figure 2). For this reason, the pertinent Matlab-Simulink model is described more in detail.

Figure 3 shows the SD Simulink block input and output variables.

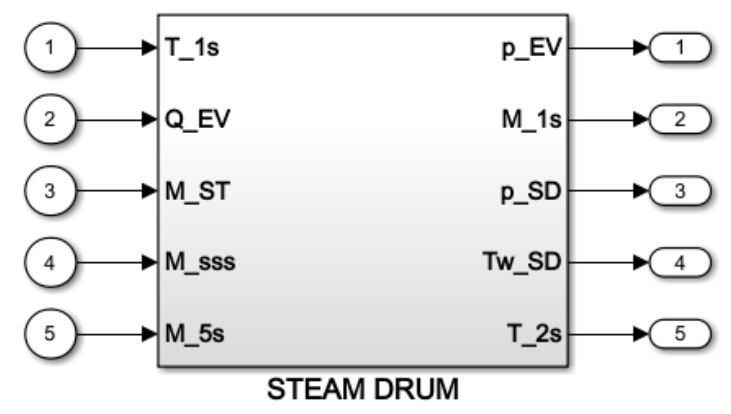

Figure 3. Steam Drum (SD) Matlab-Simulink module.

As regards input data, $T_{-} 1 s$ is the water inlet temperature (from the Economizer module as visualized from Figure 2); $Q \_E V$ is the heat exchanged, calculated through the Equation (4); $M \_S T$ is the steam mass flow rate to the steam turbine (ST in Figure 1); M_sss and M_5s, respectively, are the steam mass flow rate to the ship steam services and to the second steam condenser (2nd SCO in Figure 1).

As for output data, $p_{-} E V$ is the water/steam pressure in the evaporator outlet (EV in Figure 1); $M_{-}$1s is the economizer (E in Figure 1) water mass flow rate; $p_{-} S D$ and $T w \_S D$, respectively, are the steam drum water/steam pressure and wall temperature; $T \_2 s$ is the water/steam saturation temperature.

For the SD calculation, it is assumed that the SD volume is occupied in the lower half by the saturated liquid and in the upper one by the saturated steam [26]. This hypothesis, maintained also during the transients computation, is due to presence of a SD governor of the free surface level.

In the SD model, the dynamic energy Equation (2) is developed in the following form:

$$
\frac{d u}{d t}=\frac{1}{m_{S D}}\left[Q_{E V}+M_{1 s} h_{s l}-\left(M_{s s s}+M_{S T}+M_{5 s}\right) h_{s s}+Q w_{S D}\right]
$$

where $u$ is the specific internal energy of the water/steam saturated mass mixture in the SD volume; $m_{S D}$ is the overall water and steam mass in the SD; $M_{5 s}$ is the steam mass flow rate delivered to second steam condenser ( $2_{\text {nd }} \mathrm{SCO}$ in Figure 1$) ; h_{s l}$ and $h_{s S}$, respectively, are the SD saturated liquid and steam specific enthalpy; $Q w_{S D}$ is the heat exchanged between $S D$ inside fluid and wall one, determined by Equation (3). In Equation (4), the specific internal energy $u$ of the water/steam saturated mass mixture in the SD is defined by:

$$
u=\frac{m_{l} u_{l}+m_{s} u_{s}}{m_{l}+m_{s}}
$$

where $m_{l}$ and $m_{s}$, respectively, are the masses of the saturated liquid and steam in the SD; $u_{l}$ and $u_{s}$ are the two respective specific internal energies.

The mass flow rate $M_{5 s}$ is tapped by the SD to keep the pressure inside within the maximum value ( 8 bar, as reported in Table 2). This mass flow rate is controlled by a specific governor through the $\mathrm{SDpcV}$ valve, visualized in the WHR steam plant scheme of Figure 1.

Continuity Equation (1) is used to find the economizer outlet mass flow rate $M_{1 s}$, developed as follows:

$$
\frac{d \rho}{d t}=\frac{1}{V}\left(M_{1 s}-M_{S T}-M_{s s s}-M_{5 s}\right)
$$

where, in this case, $\rho$ is the density of the saturated water/steam mixture in the SD volume $V$. Density $\rho$ is calculated in a similar manner to the specific internal energy $u$, by: 


$$
\rho=\frac{V_{l} \rho_{l}+V_{s} \rho_{s}}{V_{l}+V_{s}}
$$

where $V_{l}$ and $V_{s}$ are the SD volumes occupied by saturated liquid and steam, respectively; $\rho_{l}$ and $\rho_{s}$ represent the respective densities. Obviously, $V_{l}$ plus $V_{s}$ is equal to the overall internal SD volume $V$.

\subsection{Steam Turbine Modeling}

Steam flow temperature and pressure are the input data to the ST simulation model, where the brake power $P_{B}$ is found through the following thermodynamic equation:

$$
P_{B}=M_{T} \eta_{T}\left(h_{i}-h_{o}\right)
$$

where $M_{T}$ is the steam mass flow rate and $\eta_{T}$ is the steam turbine efficiency. The steam flow rate $M_{T}$ depends on the throttle valve position, in accordance with the relationship provided by the ST manufacturer.

The throttle valve opening is commanded through a PID algorithm, acting on the error between the reference setpoint corresponding to the power grid frequency value and the turbogenerator revolutions, achieved from the solution of the pertinent shaft dynamic equation:

$$
\frac{d \omega}{d t}=\frac{1}{J}\left(\Theta_{S T}-\Theta_{E G}\right)
$$

where $\omega$ is the turbogenerator speed; $J$ is the polar moment of inertia of the rotating masses; $\Theta_{S T}$ is the steam turbine torque; and $\Theta_{E G}$ is the electric generator torque.

While the ST torque is obtained dividing the power of Equation (4) by the rotational speed, the electric dynamics of the alternator is not considered; under this hypothesis, the electric generator torque is derived from the ship electric power demand variation, taking into account the alternator efficiency.

The mathematical approach validation is based on reference experimental data relating to a more powerful steam turbine for terrestrial power plants, as described in Reference [27]. An idea of the accuracy of the model is given in Figure 4, where the comparison between full-scale data and simulation is shown in an example of electric power transient. Results are in percentage of the nominal power value for confidential reason; however, further details of the validation process can be found in Reference [27].

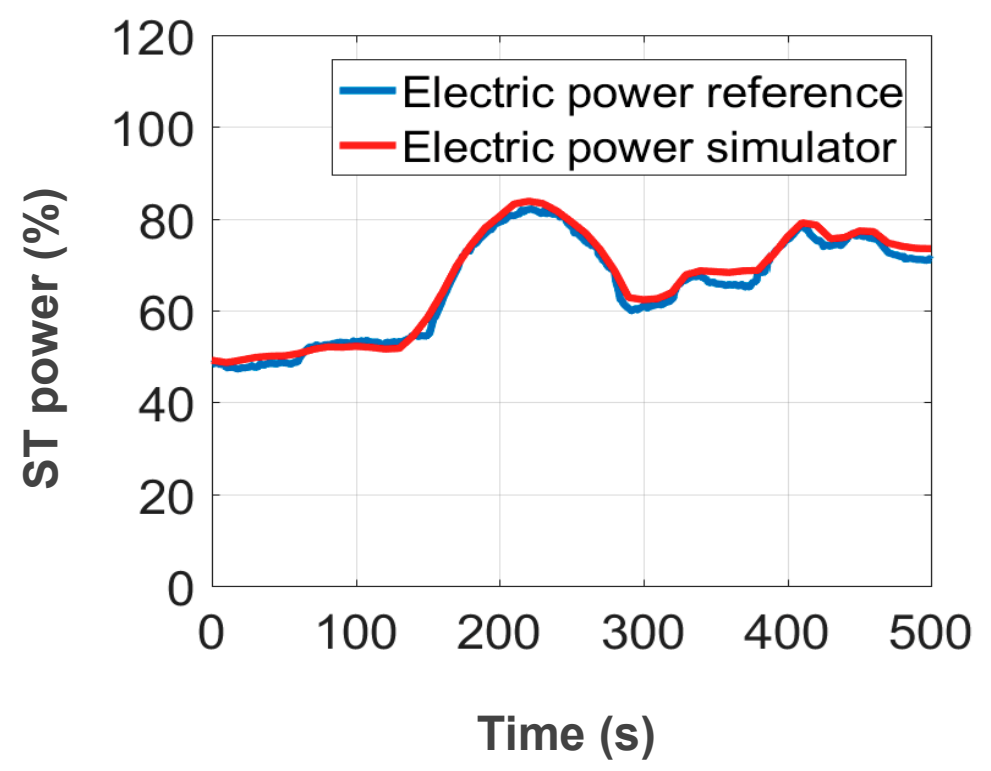

Figure 4. Steam Turbine (ST) modeling validation: comparison between reference data and simulation. 
As for the ST governor modeling, the methodology to select the PID gain values will be addressed after the presentation of some significant results in steady-state conditions.

\section{Steady-State Performance}

In order to analyze the WHR system performance in steady-state conditions, the dynamics effects due to the ST control system are irrelevant. Thus, some important results can be already shown before the governor modeling description. The electric power, produced by the turbogenerator, is then reported as a function of the DF engine load in Figure 5, where both the propulsion modes, heavy fuel oil (HFO) or LNG, are considered. From the figure, it is evident the superior performance of the examined WHR system for every engine running condition when LNG fuel is used.

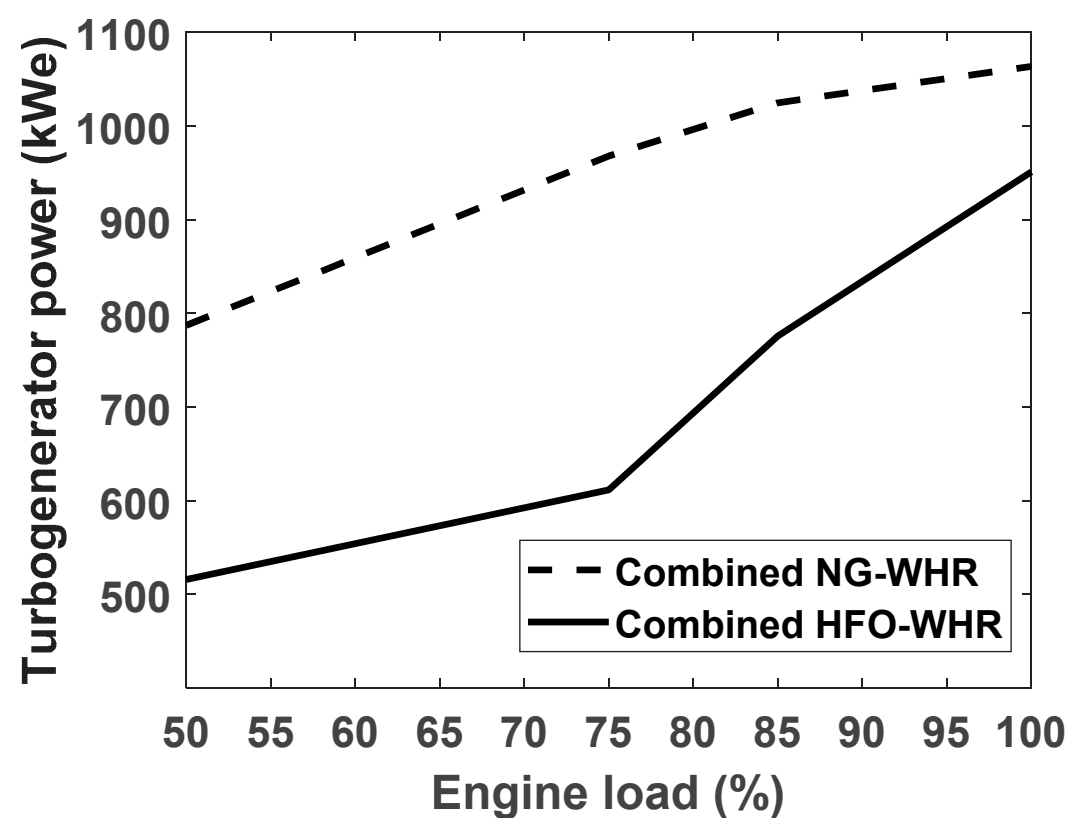

Figure 5. Turbogenerator power dependence on DF engine loads.

In particular, the best benefit is found at around $75 \%$ of the engine load, which can be reasonably supposed as a possible design propulsive point of the ship. Given the importance of this running condition, further numerical results are shown in Table 2 as a comparison between the two fuel modes of the engine.

Table 2. WHR system performance at $75 \%$ of the engine load.

\begin{tabular}{ccc}
\hline Performance Data & LNG Mode & HFO Mode \\
\hline SD pressure [bar] & 8 & 8 \\
HRSG outlet gas temperature $\left[{ }^{\circ} \mathrm{C}\right]$ & 157 & 171 \\
Ship users steam flow rate $[\mathrm{kg} / \mathrm{s}]$ & 0.15 & 0.38 \\
ST steam flow rate $[\mathrm{kg} / \mathrm{s}]$ & 2.06 & 1.30 \\
Turbogenerator power $[\mathrm{kWe}]$ & 968 & 611 \\
\hline
\end{tabular}

In the LNG engine mode, the turbogenerator can produce enough power to meet the maximum demand in electric energy of the vessel. This power surplus is certainly due to a lower temperature at the HRSG outlet but also to a minor steam demand by the ship users since the diesel oil tanks heating is avoided when natural gas is burned. 


\section{ST Governor Design: Methodology and Application}

Since electrical energy is very difficult to store on board, a permanent balance between energy production and consumption is fundamental. Mechanical and/or electrical inertias of generators, loads, and electrical networks connecting them may complicate the maintaining of a balance with relatively constant frequency and voltage. In fact, in the presence of a change in power demand, the electrical system normally resumes a stable state after a few oscillations (possible variations in power grid frequency should be comprised between $\pm 10 \%$, considering 5 seconds as recovery time [28]). However, in some cases, the oscillating state may diverge, and specific analyses are, therefore, needed to avoid this phenomenon and guarantee the stability of the electrical power grid. From this point of view, an important role could be assumed by the governor of the turbogenerator.

Therefore, in order to design the control system taking into account specific performance requirements, the methodology proposed in Reference [25] was adopted for the synthesis of the controller based on a linearized system. This procedure allows to improve the performance of the actuation process and to achieve fast repeatability of the several design steps in other similar applications.

The linear controller is then validated on the physical model described in the previous section.

In order to both maintain the PID-based controller structure and guarantee closed-loop stability properties, linear approaches for the controller design have been adopted. In particular, the controller has to limit overshooting without compromising system response time. In this context, the proposed controller synthesis is carried out by using Linear Matrix Inequalities (LMIs). Due to the fact that control problems, dealt with Lyapunov approaches, are naturally formulated by means of design inequality constraints, LMI application to the controller design and synthesis is increasing.

In order to properly implement the proposed methodology, a linear plant need to be adopted for the controller parameters synthesis. The previously detailed model is not easily linearizable due to its complex structure. Then, an identification process allows the definition of a linear model able to detect main dynamics of the model. Usually, experimental tests are used for this type of approach. In this case, since it is not possible to have measurements of system responses in full size, the detailed model has been adopted to generate the "measurement signals". Finally, on the basis of the simplified model obtained, the coefficients of the controller were computed by means of the convex optimization approach described below and the performance of the controller was validated on the detailed (physical-based) model.

\subsection{System Identification}

As previously briefly explained, experimental data for the specific application are not available. For such a reason, the physical-based model has been adopted to simulate measurements. A pseudo-random sequence was adopted in order to stress the system in a wide range of frequencies. Detailed observations of the input/output relationships shown in Figure 6 led to propose the structure reported in Equation (10) as a linear model able to estimate the turboalternator dynamics. Indeed, the linear system to be identified is:

$$
\left\{\begin{aligned}
\dot{x}= & A x+B u+E w \\
& y_{\text {lin }}=C x
\end{aligned}\right.
$$

where $x=\left[\Theta_{S T}, n\right]^{T}=\left[x_{1}, x_{2}\right]^{T}$ is the state, $u$ is the system input (required steam flow rate by means of valve position), $E$ is the external disturbances matrices (represented by the electric load applied to the turbogenerator), and:

$$
A=\left[\begin{array}{cc}
a_{11} & 0 \\
\frac{1}{2 \pi J_{p}} & 0
\end{array}\right], B=\left[\begin{array}{c}
b_{1} \\
0
\end{array}\right], C=\left[\begin{array}{ll}
1 & 0 \\
0 & 1
\end{array}\right], E=\left[\begin{array}{c}
0 \\
\frac{-1}{2 \pi J_{p}}
\end{array}\right] .
$$


The identification was performed through the function objective described in Equation (8), where $y_{\text {meas }}$ is the measured output signal, while $y_{\text {lin }}$ is the output of the linear model. The solution, obtained by minimizing the sum of the error squares, is given by parameters $\left\{a_{11}, b_{1}\right\}$ that minimize the function.

$$
\min _{x}\left\|y_{\text {meas }}-y_{\text {lin }}\right\|_{2}^{2}
$$

Figure 6 shows results compared with simulated measures. As can be seen, the model is able to properly detect prevailing dynamics by means of time response and steady-state. The model is strictly nonlinear. For such a reason the steady-state can present some errors that will be compensated with the integral action of the controller.

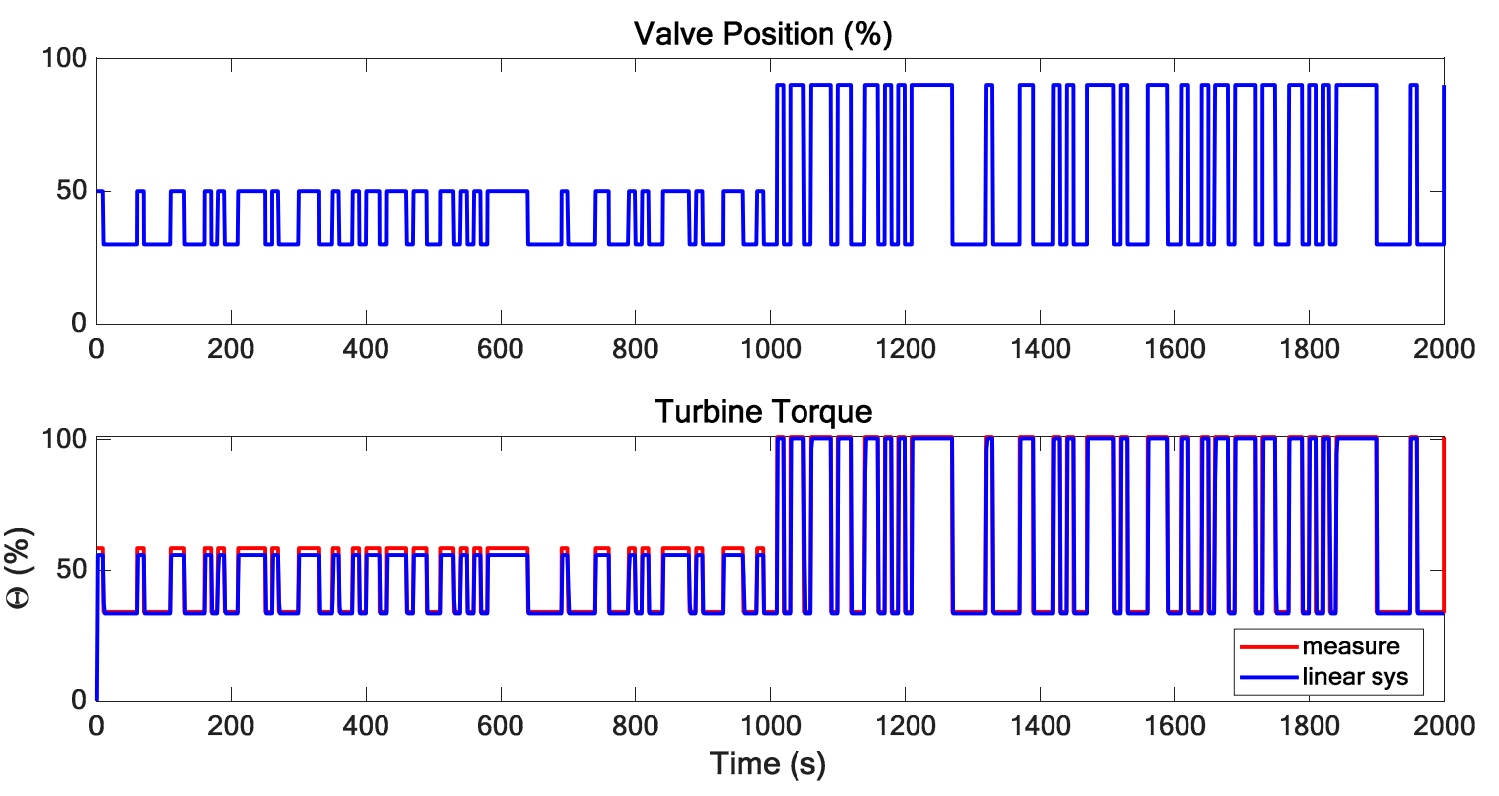

Figure 6. Model identification results.

\subsection{Controller Design and Synthesis}

The objective of the controller is to evaluate the steam flow rate necessary to keep the shaft speed rate constant (i.e., constant network frequency). In particular, a PI (proportional-integral) regulator is commonly chosen for this application. In order to facilitate parameter tuning, the controller synthesis based on LMIs is proposed [29]. Indeed, LMI techniques allow to solve control problems by means of convex formulations. In the present case study, the computation of the feedback gain for the linear time-invariant, sketched in Figure 7, system is evaluated via LMI solution. The regulator can be represented as:

$$
u=K_{P} e_{n}+K_{I} \int_{0}^{t} e_{n}(\zeta) \mathrm{d} \zeta
$$

where the scalar parameters $K_{P}$ and $K_{I}$ are suitably chosen in such a way to ensure closed-loop stability and $e_{n}=n_{d}-x_{2}$ is the shaft speed error. Thus, the closed-loop dynamics is:

$$
\left\{\begin{array}{c}
\dot{x}_{1}=a_{11} x_{1}-b_{1} K_{P} x_{2}+b_{1} K_{I} x_{3}-b_{1} K_{P} n_{d} \\
\dot{x}_{2}=\frac{1}{2 \pi j} x_{1}-\frac{1}{2 \pi j} w \\
\dot{x}_{3}=n_{d}-x_{2}
\end{array}\right.
$$

By defining $K_{1} b_{1} K_{P}$ and $K_{2}-b_{1} K_{I}$, the differential equation system can be equivalently written as follows:

$$
\dot{x}=(A-B K) x+\bar{E} \bar{w}
$$


where:

$$
\bar{E}=\left[\begin{array}{cc}
-b_{1} K_{P} & 0 \\
0 & -\frac{1}{2 \pi J} \\
1 & 0
\end{array}\right] \bar{w}=\left[n_{d}, w\right]^{T}
$$

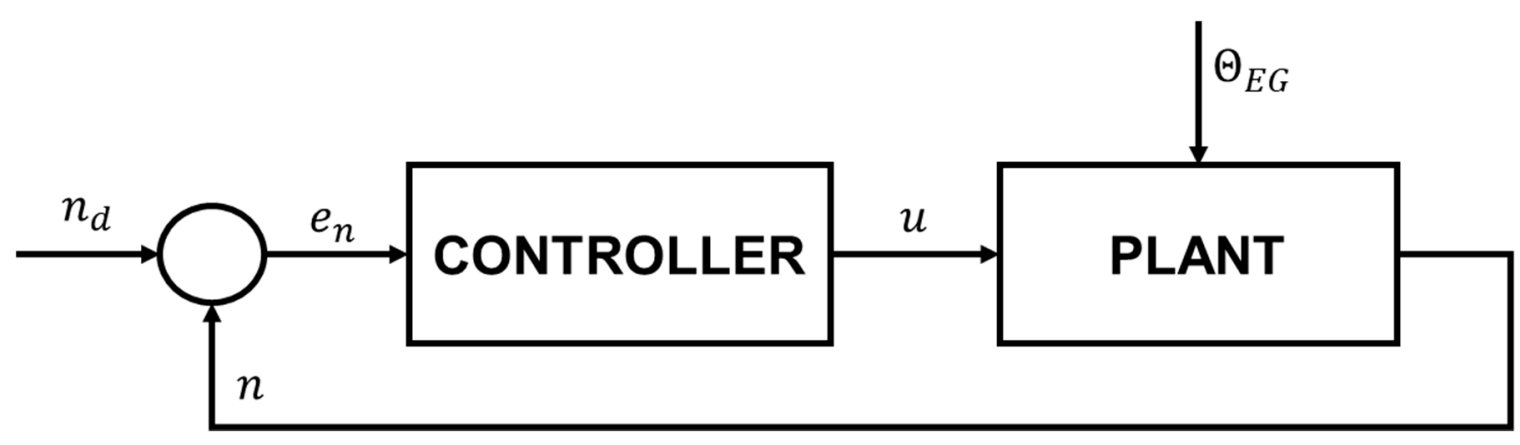

Figure 7. Closed-loop structure.

The system (11a) is quadratically stabilizable if there exists a state-feedback gain $\mathrm{K}$ such that exists a Lyapunov function $V(x)=x^{T} Q x$, with $Q$ symmetric positive definite matrix such that the time derivative of $V(x)$ is strictly negative for all $x$. Such a condition corresponds to find $\mathrm{K}$ such that

$$
(A-B K)^{T} Q+Q(A-B K)<0
$$

As shown in Reference [26], (12) can be expressed in an equivalent way by pre- and post-multiplying for $Q^{-1}$ as follows

$$
Q^{-1}(A-B K)^{T}+(A-B K) Q^{-1}<0
$$

and being $P Q^{-1}$ and $Y=K P$; the following the resulting $L M I$ corresponds to sol

$$
\begin{array}{cc}
\text { minimize } & \operatorname{Tr} Q \\
\text { subject to } & P>0 \\
& P A^{T}-A P+Y^{T} B^{T}-B Y<0
\end{array}
$$

After solving (14), the gain $K=P^{-1} Y$ and thus the values of $K_{P}$ and $K_{I}$ can be obtained.

After identifying the dominant dynamics of the closed-loop model, it is possible to evaluate the transfer functions of the controlled system. This enables the presence of the system to be taken into account in a more general simulation of similar applications. Using the Laplace transform, the structure of the relationship between the variation in the number of revolutions and the applied load is obtained:

$$
H(s)=\frac{n_{2} s^{2}+n_{1} s+n_{0}}{d_{3} s^{3}+d_{2} s^{2}+d_{1} s+d_{0}}
$$

where $n_{i}$ and $d_{j}$ are the coefficients of the numerator and denominator polynomials, respectively.

By Equation (15) it is possible to reproduce the alternator speed response by following the application of the variation in the electrical load. The function describes the dynamic behavior of the turbogenerator, including governor and shaft dynamics. The simplification may be useful for a direct stability analysis of the power grid, taking into account the turbogenerator as a single component or integrated into other elements of the whole electrical system.

\section{Dynamic Simulation Results}

The results for the closed-loop system are presented in this section. In order to analyze the proposed methodology for the PID gains synthesis with the linear time-invariant plant, the controller 
has been validated with the detailed model described in Section 3. In particular, the response of the system and controller performances are illustrated for different setpoint time histories (by means of steps). Figures 8-10 show the shaft speed errors and the steam turbine response to specific steps. In particular, the shaft speed error is reported on the top: red lines are the setpoints whereas dashed blue lines are the measured errors. Figure 8 shows results of the system with rising and falling steps of electric load. As can be seen, the torque follows the generator load also with huge variations. Shaft speed error is lower than 3\% for the whole simulation. On the bottom, the comparison between the torque applied to the electric generator (red lines) and the steam turbine delivered torque (dashed blue lines) are reported. In all the considered figures, the shaft speed error is kept limited by the controller and some small variations are smoothly converging to zero when high magnitude steps are the input, i.e., Figure 9. Indeed, the main aim of the presented controller is to limit dangerous torque overshoots without affecting the controller structure itself. Figure 10 shows response to falling steps. Shaft speed variations are kept small and the steam turbine torque is able to properly follow the load applied to the electric generator.

The analyzed system is very fast in terms of response, so it has been possible to obtain smooth responses while keeping the smooth controller output.
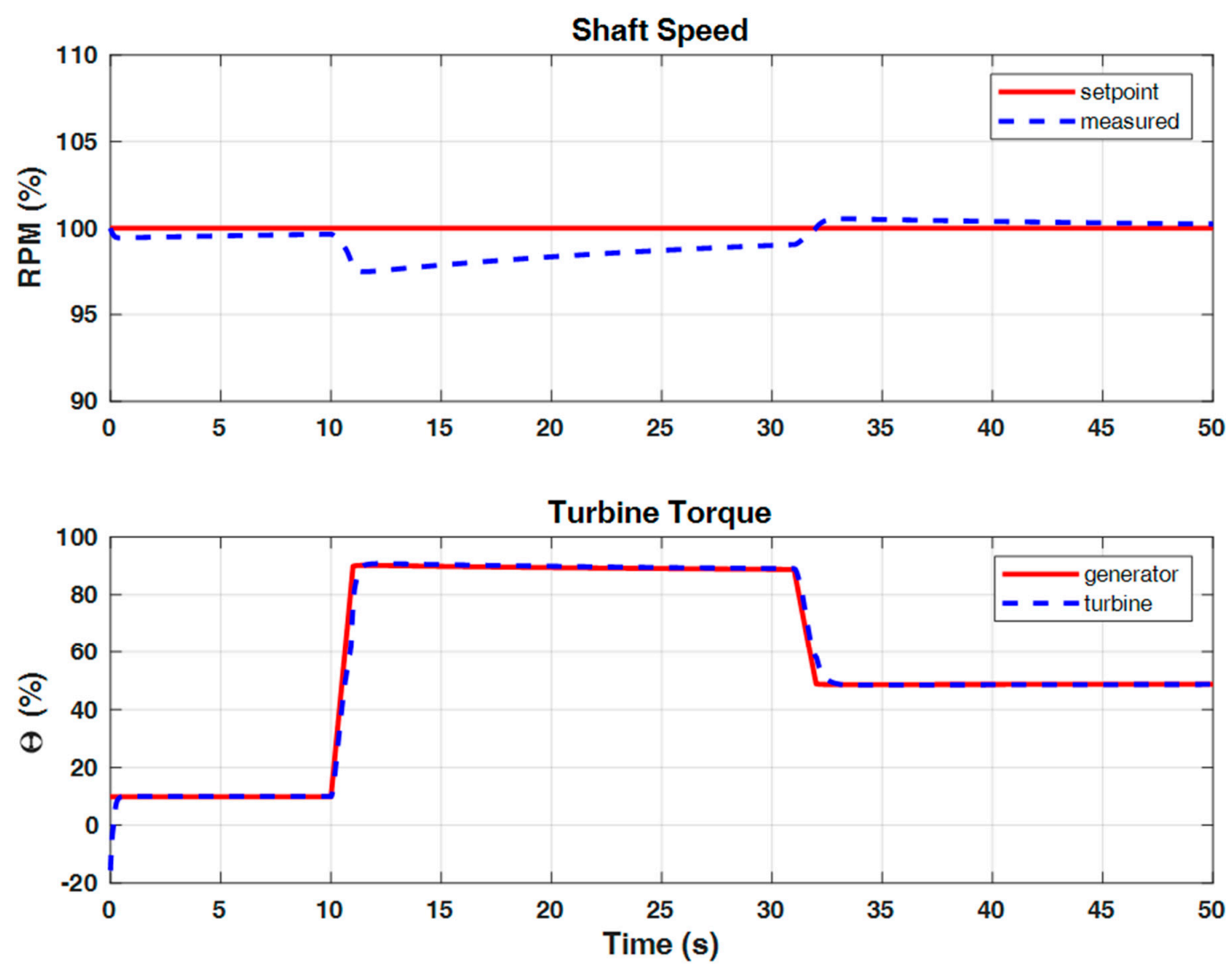

Figure 8. Closed-loop response to rising and falling steps. 

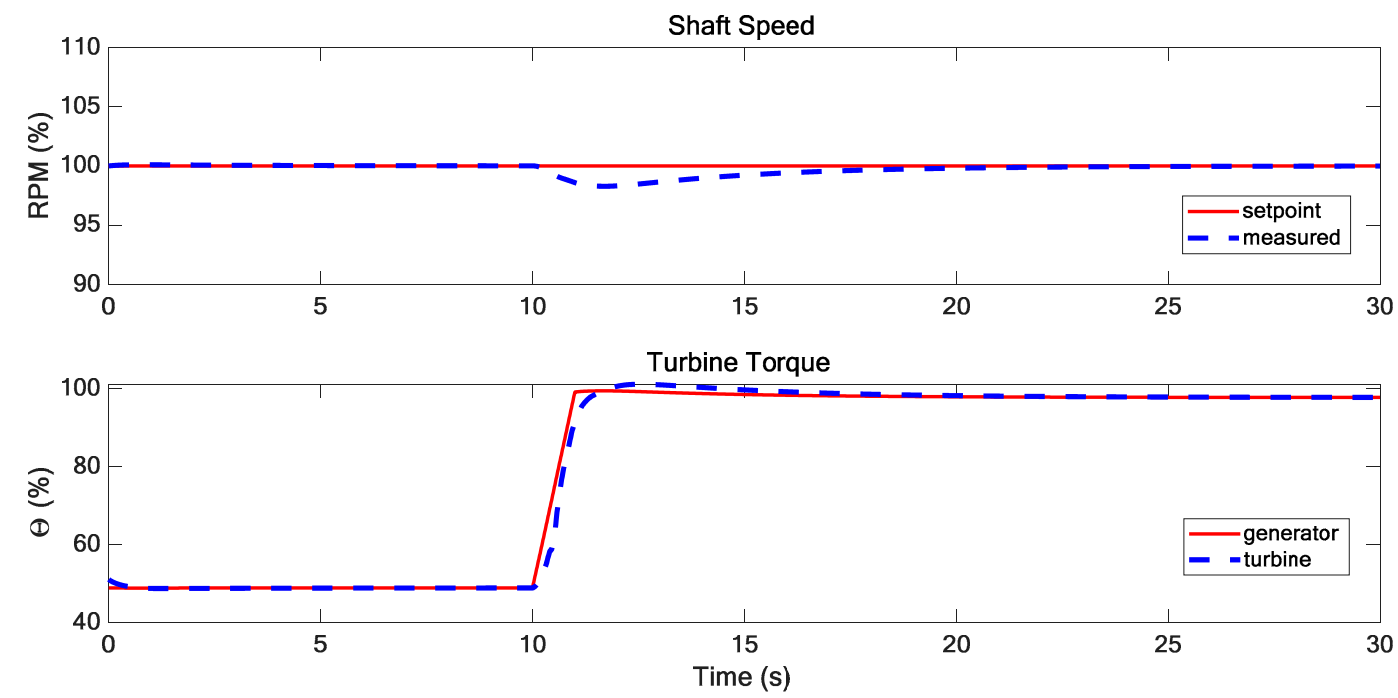

Figure 9. Closed-loop response to rising step.
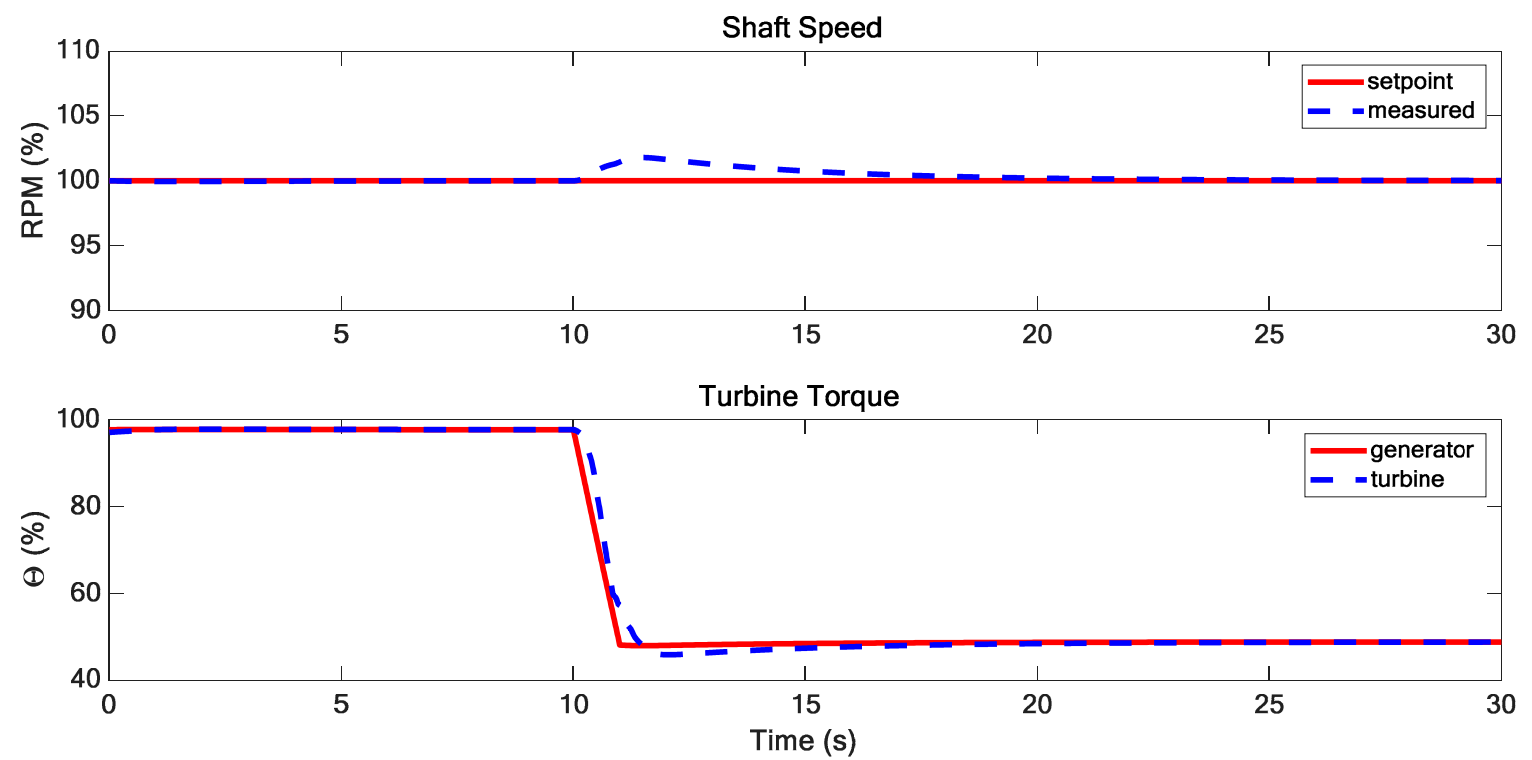

Figure 10. Closed response to falling step.

\section{Conclusions}

As first objective of the present study, the performance analysis of a combined DF engine-WHR steam plant is shown by numerical simulation to estimate ship energy efficiency improvements. The best benefits are mainly found in the gas propulsion mode of the ship since the greater availability of steam (achieved from recovering the waste heat of the main engine) allows to power a more powerful turbogenerator compared to a diesel propulsion application. The reason is due to a lower temperature of the engine exhaust gas at the funnel outlet that is possible to exploit for steam production. This is possible because sulfur emissions are canceled in LNG mode and, therefore, the sulfuric acid does not form in the components of the heat recovery steam generator.

In the examined case study, concerning a single screw merchant ship, the steam flow rate produced by the WHR system is almost twice higher in the gas fuel mode of the main engine, and a single steam-powered turbogenerator can completely meet the ship electric power demand during navigation.

Due to the complexity of the system, the check of its correct sizing in the design stage should be carried out even in transient conditions, especially during critical variations in electric power demand. Thus, the system dynamic behavior has been investigated to test the electric power grid stability. 
To this end, a specific procedure for the controller design and synthesis of a PI regulator for the steam turbine has been presented as second important objective of the work. The basic idea is to select the controller gains by means of a linearized system and to validate them on the detailed one. Such a methodology has been proved to be a satisfactory tool for the approach to the ST governor design. In addition, the definition of the linearized model has allowed to identify the general structure of a transfer function for a simplified representation of the turbogenerator behavior, to be used more easily in any stability analysis of electric power grids. Nevertheless, the proposed linear model should be improved in further studies as well as the possibility to add a non-overshooting condition in the LMI problem constraints.

Author Contributions: Conceptualization, M.A. and U.C.; methodology, U.C., M.A., and S.D.; software, M.A. and R.Z.; writing—original draft preparation, M.A. and S.D.; writing-review and editing, M.A., S.D., and R.Z.; supervision, M.A. and S.D.

Funding: This research received no external funding.

Acknowledgments: The authors wish to acknowledge the data support given by Fincantieri S.p.A., Genoa, Italy.

Conflicts of Interest: The authors declare no conflict of interest.

\section{References}

1. International Maritime Organization (IMO). Report of the Marine Environment Protection Committee (MEPC) on its 57th Session; International Maritime Organization: London, UK, 2008.

2. International Maritime Organization (IMO). International Convention for the Prevention of Pollution from Ships (MARPOL) Annex VI; International Maritime Organization: London, UK, 2011.

3. International Maritime Organization (IMO). Marine Environment Protection Committee (MEPC), 66th Session; International Maritime Organization: London, UK, 2014.

4. International Maritime Organization (IMO). Interim Guidelines on the Method of Calculation of the Energy Efficiency Design Index (EEDI) for New Ships; In MEPC 1/Circ: 681; International Maritime Organization: London, UK, 2009.

5. International Maritime Organization (IMO). Guidelines to the Method of Calculation of the Attained Energy Efficiency Design Index (EEDI) for New Ships; In MEPC 212 (63/23); Annex 8; International Maritime Organization: London, UK, 2012.

6. Altosole, M.; Figari, M.; Martinelli, L.; Raimondi, M. Hybrid propulsion by gas engines for an ASD harbour tug. In Proceedings of the 17th International Conference on Ships and Shipping Research, NAV 2012, Naples, Italy, 17-19 October 2012.

7. Altosole, M.; Buglioni, G.; Figari, M. Alternative propulsion technologies for fishing vessels: A case study. Int. Rev. Mech. Eng. 2014, 8, 296-301.

8. Pedersen, M.F. Emission Standards; DieselNet: Mississauga, ON, Canada, 2015.

9. Altosole, M.; Benvenuto, G.; Campora, U.; Laviola, M.; Zaccone, R. Simulation and performance comparison between diesel and natural gas engines for marine applications. Proc. Inst. Mech. Eng. Part. M J. Eng. Marit. Environ. 2017, 231, 690-704. [CrossRef]

10. Schmid, H. Less emissions through waste heat recovery. In Proceedings of the Green Ship Technology Conference, London, UK, 28-29 April 2004.

11. Theotokatos, G.; Livanos, G. Exhaust gas waste heat recovery in marine propulsion plants. In Proceedings of the 14th International Conference on Maritime Association of Mediterranean, IMAM 2011, Genova, Italy, 13-16 September 2011; Soares, C.G., Rizzuto, E., Eds.; CRC Press/Balkema: Boca Raton, FL, USA, 2012.

12. Altosole, M.; Laviola, M.; Trucco, A.; Sabattini, A. Waste heat recovery systems from marine diesel engines: Comparison between new design and retrofitting solutions. In Maritime Technology and Engineering. In Proceedings of the 2nd International Conference on Maritime Technology and Engineering, MARTECH 2014, Lisbon, Portugal, 14-17 October 2014; Soares, C.G., Santos, T.A., Eds.; CRC Press/Balkema: Boca Raton, FL, USA, 2015.

13. Altosole, M.; Benvenuto, G.; Campora, U.; Laviola, M.; Trucco, A. Waste heat recovery from marine gas turbines and diesel engines. Energies 2017, 10, 718. [CrossRef] 
14. Livanos, G.A.; Theotokatos, G.; Pagonis, D.N. Techno-economic investigation of alternative propulsion plants for Ferries and RoRo ships. Energy Convers. Manag. 2014, 79, 640-651. [CrossRef]

15. Altosole, A.; Campora, U.; Laviola, M.; Zaccone, R. Waste heat recovery from dual-fuel marine engines. In Maritime Transportation and Harvesting of Sea Resources. In Proceedings of the 17th International Congress of the International Maritime Association of the Mediterranean, IMAM 2017, Lisbon, Portugal, 9-11 October 2017; Soares, C.G., Teixeira, A.P., Eds.; CRC Press/Balkema: Boca Raton, FL, USA, 2017.

16. Altosole, A.; Campora, U.; Savio, S. Improvements of the ship energy efficiency by a steam powered turbogenerator in LNG propulsion applications. In Proceedings of the International Symposium on Power Electronics, SPEEDAM 2018, Amalfi, Italy, 20-22 June 2018; pp. 449-455.

17. Altosole, A.; Campora, U.; Laviola, M.; Zaccone, R. High Efficiency waste heat recovery from dual fuel marine engines. In technology and science for the ships of the future. In Proceedings of the 19th International Conference on Ship and Maritime Research, NAV 2018, Trieste, Italy, 20-22 June 2018; Marino, A., Bucci, V., Eds.; Associazione Italiana di Tecnica Navale: Genoa, Italy, 2018.

18. Man Diesel \& Turbo. Waste Heat Recovery System (WHRS) for Reduction of Fuel Consumption, Emissions and EEDI; Man Diesel \& Turbo: Copenhagen, Denmark, 2011.

19. Lucia, U.; Grisolia, G. Exergy inefficiency: An indicator for sustainable development analysis. Energy Rep. 2019, 5, 62-69. [CrossRef]

20. Altosol, M.; Figari, M.; Bagnasco, A.; Maffioletti, L. Design and test of the propulsion control of the aircraft carrier "Cavour" using real-time hardware in the loop simulation. In Proceedings of the SISO European Simulation Interoperability Workshop 2007, EURO SIW 2007, Genoa, Italy, 18-20 June 2007; pp. 67-74.

21. Altosole, M.; Benvenuto, G.; Figari, M.; Campora, U.; Bagnasco, A.; D’Arco, S.; Giuliano, M.; Giuffra, V.; Spadoni, A.; Zanichelli, A.; et al. Real time simulation of the propulsion plant dynamic behaviour of the Aircraft Carrier "Cavour". In Proceedings of the 9th International Naval Engineering Conference and Exhibition: Embracing the Future, INEC 2008, Hamburg, Germany, 1-3 April 2008.

22. Michetti, S.; Ratto, M.; Spadoni, A.; Figari, M.; Altosole, M.; Marcilli, G. Ship Control system wide integration and the use of dynamic simulation techniques in the Fremm project. In Proceedings of the International Conference on Electrical Systems for Aircraft, Railway and Ship Propulsion, ESARS 2010, Bologna, Italy, 19-21 October 2010.

23. Altosole, M.; Benvenuto, G.; Figari, M.; Campora, U. Real-time simulation of a COGAG naval ship propulsion system. In Maritime Industry, Ocean Engineering and Coastal Resources. In Proceedings of the 12th International Congress of the International Maritime Association of the Mediterranean, IMAM 2007, Varna, Bulgaria, 2-6 September 2007; pp. 331-337.

24. Altosole, M.; Martelli, M. Propulsion control strategies for ship emergency manoeuvres. Ocean Eng. 2017, 137, 99-109. [CrossRef]

25. Marchelli, L. Modellazione Numerica del Comportamento Dinamico di una Turbina a Vapore per Applicazioni Navali. Master's Thesis, University of Genova, Genova, Italy, 2018.

26. Shin, J.Y.; Jeon, Y.J.; Maeng, D.J.; Kim, J.S.; Ro, S.T. Analysis of the dynamic characteristics of a combined-cycle power plant. Energy 2002, 27, 1085-1098. [CrossRef]

27. MAN Energy Solutions. 51/60DF Project Guide; MAN Energy Solutions: Augsburg, Germany, 2014.

28. RINA. Rules for the Classification of Ships; Part C, Chapter 2, Section 2; RINA: Genoa, Italy, 2017.

29. Alessandri, A.; Donnarumma, S.; Vignolo, S.; Figari, M.; Martelli, M.; Chiti, R.; Sebastiani, L. System control design of autopilot and speed pilot for a patrol vessel by using LMIs. Towards Green Mar. Technol. Transp. 2015, 577-583. [CrossRef]

(C) 2019 by the authors. Licensee MDPI, Basel, Switzerland. This article is an open access article distributed under the terms and conditions of the Creative Commons Attribution (CC BY) license (http://creativecommons.org/licenses/by/4.0/). 